\title{
Review Article \\ Evidence for Resistance Training as a Treatment Therapy in Obesity
}

\author{
Barbara Strasser and Wolfgang Schobersberger \\ Institute for Sports Medicine, Alpine Medicine and Health Tourism, University for Health Sciences, \\ Medical Informatics and Technology, 6060 Hall in Tirol, Austria
}

Correspondence should be addressed to Barbara Strasser, barbara.strasser@umit.at

Received 14 May 2010; Accepted 16 June 2010

Academic Editor: Eric Doucet

Copyright (C) 2011 B. Strasser and W. Schobersberger. This is an open access article distributed under the Creative Commons Attribution License, which permits unrestricted use, distribution, and reproduction in any medium, provided the original work is properly cited.

\begin{abstract}
Over the last decade, investigators have paid increasing attention to the effects of resistance training (RT) on several metabolic syndrome variables. Evidence suggests that skeletal muscle is responsible for up to $40 \%$ of individuals' total body weight and may be influential in modifying metabolic risk factors via muscle mass development. Due to the metabolic consequences of reduced muscle mass, it is understood that normal aging and/or decreased physical activity may lead to a higher prevalence of metabolic disorders. The purpose of this review is to (1) evaluate the potential clinical effectiveness and biological mechanisms of RT in the treatment of obesity and (2) provide up-to-date evidence relating to the impact of RT in reducing major cardiovascular disease risk factors (including dyslipidaemia and type 2 diabetes). A further aim of this paper is to provide clinicians with recommendations for facilitating the use of RT as therapy in obesity and obesity-related metabolic disorders.
\end{abstract}

\section{Introduction}

The inclusion of resistance training (RT) as an integral part of an exercise therapy program has been endorsed by the American Heart Association [1], the American College of Sports Medicine [2], and the American Diabetes Association [3]. While these recommendations are primarily based on the effects of RT on muscle strength, cross-sectional studies have shown that muscle mass is inversely associated with all-cause mortality [4] and the prevalence of the metabolic syndrome [5], independent of cardiorespiratory fitness levels.

Aging is associated with a loss of both muscle mass and the metabolic quality of skeletal muscle. Sarcopenia, the loss of muscle mass associated with aging, is a main cause of muscle weakness in old age and leads consequently to an increased risk for development of obesity-associated insulin resistance and type 2 diabetes mellitus [6]. Research supports the use of RT to prevent an age-related decline in skeletal muscle mass (which is approximately $0.46 \mathrm{~kg}$ of muscle per annum from the fifth decade on). Strong evidence indicates that muscle maintains its plasticity and capacity to hypertrophy, even into the 10th decade of life [7-9]. However, there is some evidence to suggest that muscle strength and its effect on body composition and metabolic risk factors may be more important than muscle mass [10]. Accordingly, the term of "dynapenia" to qualify the loss of muscle strength with normal aging has been proposed [11]. A number of neural factors may be implicated in the ageassociated loss of muscle strength, but also alterations in contractile properties are discussed.

Skeletal muscle is the primary metabolic target organ for glucose and triglyceride disposal and is an important determinant of resting metabolic rate. The potential consequences of age-related reduction in skeletal muscle mass are diverse, including reduced muscle strength and power, reduced resting metabolic rate, reduced capacity for lipid oxidation, and increased abdominal adiposity. With increasing adiposity, the insulin-mediated glucose uptake in skeletal muscle of elderly patients is reduced [12]. Evidence suggests that the maintenance of a large muscle mass may reduce metabolic risk factors-namely, obesity, dyslipidaemia, and type 2 diabetes mellitus-associated with cardiovascular 
disease [13-15]. Despite the fact that a high muscle mass is associated with a favourable metabolic profile, one study reported that a higher muscle mass can be associated with metabolic disturbances in obese women [16]. The possible mechanisms may include increased concentrations of free androgens due to diminished levels of SHBG, a proteinsparing effect due to increased lipid metabolism, and changes in muscle capillarization and fiber composition due to visceral adiposity.

For the most part, recommendations to treat or prevent overweight and obesity via physical activity have focused on aerobic endurance training (AET). Data suggest that RT may be an effective alternative for modifying metabolic risk factors. From this backdrop, the purpose of this review is to (1) evaluate the potential clinical effectiveness and biological mechanisms of RT in the treatment of obesity and (2) provide-up-to-date evidence on the impact of RT in reducing cardiovascular disease (CVD) risk factors, namely, dyslipidaemia and type 2 diabetes.

\section{Metabolic Effects of Resistance Training}

2.1. Weight Control. Both resting and activity-related energy expenditure declines with age [17]; decreased energy expenditure can have a major adverse effect on weight maintenance [18]. Studies on the usefulness of RT in the context of weight loss have demonstrated mixed results. Although it is clear that AET is associated with much greater energy expenditure during the exercise session than RT, some studies have shown that regular RT is effective in promoting weight loss in obese persons $[19,20]$. A significant number of studies have shown that RT is associated with a decrease in fat mass (FM) and a concomitant increase in lean body mass (LBM) and thus has little or no effective change in total body weight [21-27]. RT increased muscle mass by a minimum of 1 to $2 \mathrm{~kg}$ in studies of sufficient duration.

The implementation of RT within a dietary intake restriction programme has been studied, along with a combined dietary restriction and AET programme [28-32]. In terms of relative effects, the addition of RT has been found to prevent the loss of LBM, secondary to dietary restriction [33, 34]. One study demonstrated that twice-weekly RT could prevent age-associated loss of LBM, as well as associated resting metabolic rate (RMR) which is closely correlated to losses in LBM [35]. RT contributes to elevations of RMR as a result of a greater muscle protein turnover [36]. Theoretically, a gain of $1 \mathrm{~kg}$ in muscle mass should result in an RMR increase of approximately $21 \mathrm{kcal} / \mathrm{kg}$ of new muscle. Thus, RT, when sustained over years or decades, translates into clinically important differences in daily energy expenditure and ageassociated fat gains. For example, a difference of $5 \mathrm{~kg}$ in LBM translates to a difference in energy expenditure of $100 \mathrm{kcal}$ per day (equivalent to $4.7 \mathrm{~kg}$ FM per year) [37]. However, a number of studies have shown that RT will increase RMR, at least if the training is intense enough to induce an increase in LBM [38-40].

In a randomized control trial [41], 35 overweight men were randomized to either a control group, a diet-only group, a diet group that performed AET, or a diet group that performed both AET and RT. After 12 weeks, the weight loss in the three intervention groups was similar and significant, of which $69 \%, 78 \%$, and $97 \%$, respectively, were accounted for by fat loss. This study highlights the potential for RT to provide a unique stimulus to spare catabolism of body protein, thus altering the relationship between the LBM and FM. Exercise provided no additional stimulus for greater weight loss compared with that obtained from dietary restriction alone. The diet-only group also demonstrated a significant reduction in LBM.

Another study randomly assigned 29 obese men to one of three 16-week treatments, which consisted of a hypocaloric diet alone or in combination with RT (at $80 \%$ of 1-RM) or AET [19]. Whereas reduction in weight $(-12.4 \mathrm{~kg})$ and total adipose tissue $(-9.7 \mathrm{~kg})$ were not significantly different between the three groups, LBM was only preserved after the exercise training (independent of the mode), compared with the diet-only group $(-2.5 \mathrm{~kg})$. The principal finding of this study was that dietary restriction combined with either AET or RT increased the influence of diet alone on insulin levels in obese men.

A further trial assessed whether increases in LBM and decreases in FM from 15 weeks of twice weekly supervised RT (at $80 \%$ of $1-\mathrm{RM}$ ) could be maintained over 6 months of unsupervised exercise [25]. Over the total 39 weeks of RT, the treatment group gained $0.89 \mathrm{~kg}$ more in LBM, lost $0.98 \mathrm{~kg}$ more in FM, and lost $1.63 \%$ more in percent body fat when compared to the control group. Findings demonstrated that twice weekly RT did not result in any significant weight loss, but potentially could prevent age-associated fat gains over a period of years. Cited as feasible, was the likelihood that the positive body composition changes associated with RT could be maintained in an unsupervised exercise program after completion of the supervised exercise regime.

In a more recent study [42], an 8-week regime of RT delivered 3 times weekly (at $60 \%$ of 1-RM) significantly changed participants' body mass $(+0.58 \%)$, percentage of body fat $(-13.05 \%)$, LBM $(+5.05 \%)$, and FM $(-12.11 \%)$ when compared to the control group. This study supported a relationship between RT and body mass index (BMI), demonstrated by an increase in BMI. Therefore, the use of BMI in ascribing CVD risk should be used with caution in those individuals with an increased LBM (as would be expected following RT).

More recently, the effects of a 6-month RT program (at $50 \%$ to $80 \%$ of $1-\mathrm{RM}$ ) were analysed in relation to exerciseinduced oxidative stress and homocysteine and cholesterol in normal-weight and overweight older adults [43]. Oxidative stress is suggested to be a potential contributor in the early and advanced stages of CVD [44]. In the study, 49 older adults were stratified by BMI and randomly assigned to either a control nonexercise group or an RT group. Findings demonstrated that lipid hydroperoxides (PEROXs) and homocysteine levels were lower in both the overweight and normal weight RT groups compared with control groups. Change in muscle strength was associated with homocysteine at 6 months, whereas the change in PEROXs was associated with the change in body fat. This 
study showed that RT reduces exercise-induced oxidative stress and homocysteine, regardless of adiposity. Such a result indicates that this protection can be afforded in an older, overweight/obese population as effectively as in healthy older adults, which might indicate protection against oxidative insults (i.e., ischemia). A potential mechanism for RT-induced reduction of oxidative stress could include contraction-induced antioxidant enzyme up-regulation [45].

2.2. Visceral Adipose Tissue. Adipose tissue is a major endocrine organ, secreting substances such as adiponectin, leptin, resistin, tumor necrosis factor $\alpha$, interleukin 6 , and plasminogen activator inhibitor-1 that may play a critical role in the pathogenesis of the metabolic syndrome [46]. Excessive central obesity and especially visceral adipose tissue have been linked with the development of dyslipidaemia, hypertension, insulin resistance, type 2 diabetes, and CVD $[8,12]$. A relative increase in body fat is linked with a decline in insulin sensitivity in both obese and elderly individuals $[47,48]$.

Several studies have demonstrated decreases in visceral adipose tissue after RT programs [24, 26-28, 49, 50]. Treuth et al. observed significant decreases in visceral fat in older men and women after 16 weeks of RT [26, 27]. In two studies, Ross et al. measured regional fat losses after 16 weeks of exercise combined with dietary interventions in middle-aged obese men [28, 49]. In their first study [49], tests of both diet plus AET and diet plus RT (at 70\% to $80 \%$ of $1-\mathrm{RM}$ ) elicited similar losses of visceral fat, which were greater than losses of whole-body subcutaneous fat. In a follow-up study [28], they isolated the effects of AET and RT (at $70 \%$ to $80 \%$ of $1-\mathrm{RM}$ ) by comparing the responses to diet alone. All 3 groups lost significant amounts of total body fat, and all 3 groups experienced a significantly greater visceral fat loss compared with wholebody subcutaneous fat loss. The changes amounted to a $40 \%$ reduction in visceral fat in the diet plus RT group, $39 \%$ in the diet plus AET group, and a $32 \%$ reduction in the diet-only group. One study raised the possibility of gender specificity in visceral fat reduction response to RT [24]. Hunter et al. studied older women and men after 25 weeks of RT (at $65 \%$ to $80 \%$ of 1 -RM). Results demonstrated that both genders significantly increased muscle mass and decreased whole-body fat mass. However, women also lost a significant amount of subcutaneous and visceral adipose tissue $(-6 \%$ and $-11 \%$, resp.), whereas the men did not.

Although more research is needed to clarify these possible gender-specific responses, the overall available body of literature supports the use of RT, with or without AET, and with or without diet modification, as an effective intervention in the reduction of abdominal obesity. It seems that RT has the potential to reduce visceral fat deposits through both immediate effects (e.g., during weight loss or weight maintenance) and delayed effects (during weight regain). The results of the two Ross et al. studies [28, 49] suggest a potential for low volume, high-intensity RT to achieve reductions in total and regional adipose tissue when used in conjunction with a calorie-restriction diet. However, this observation requires confirmation by additional studies.

Overall, strong evidence supports the notion that regular RT can effectively alter body composition in obese men and women, independently from dietary restriction. It has been shown that RT increases LBM, muscular strength, and resting metabolic rate, and mobilizes the visceral and subcutaneous adipose tissue in the abdominal region. Further, RT lowers exercise-induced oxidative stress and homocysteine levels in overweight and obese older adults, associated with CVD. Considering the benefits of RT on body composition in obese men and women, the question is are there any studies that have investigated the effects of RT in obese adolescents? The majority of RT research with children to date has focused on preadolescents and the safety and efficacy of this type of training rather than the potential metabolic health benefits. There is only a small amount of evidence that children and adolescents may derive metabolic health-related adaptations from supervised RT. However, methodological limitations within the body of this literature make it difficult to determine the optimal RT prescription for metabolic fitness in children and adolescents, and the extent and duration of such benefits. More robustly designed single modality randomized controlled trials utilizing standardized reporting and precise outcome assessments are required to determine the extent of health outcomes attributable solely to RT and to enable the development of evidence-based obesity prevention and treatment strategies in this cohort. Furthermore, further studies with postintervention followups of at least six months are required in order to assess whether RT prescriptions can be maintained as part of a regular lifestyle, and whether improved body composition can be maintained over longer periods.

2.3. Metabolic Risk Reduction. Epidemiologic studies show a strong association for obesity with CVD [51] and type 2 diabetes (T2D) [52]. Obesity-induced risk factors such as plasma cholesterol, elevated plasma glucose, and elevated blood pressure increase the risk for CVD and have thus been called the "metabolic complications" of obesity [53]. Published evidence indicates that the risk for CVD associated with the metabolic syndrome is greater than the sum of its individual risk factors [54]. Apparent is that improved glycemic control, decreased fat mass, improved blood lipid profiles, and decreased blood pressure are important factors in reducing coronary heart disease $(\mathrm{CHD})$ in people with metabolic risk.

2.3.1. Dyslipidaemia. At present, a small amount of conflicting data exists on the effects of RT on blood lipid levels in healthy elderly people, and in patients with dyslipidaemia. In a recent trial, 131 subjects were randomly assigned to an RT group, an AET group, a combined RT and AET group, or a nonexercising control group [55]. Findings demonstrated that exercise mode did not impact upon blood lipids. In contrast, total cholesterol (TC), low-density lipoprotein cholesterol (LDL), and plasma triglyceride (TG) were significantly lower in all groups. These data are 
comparable with another study that investigated the effects of RT and AET on metabolic parameters in 60 obese women [56]. After 20 weeks of training without diet, significant decreases in TG and TC levels were noted in each of the study groups. Fahlman et al. demonstrated that both AET and RT groups experienced increased high-density lipoprotein cholesterol (HDL-C) and decreased TG at the end of a 10week training period in 45 healthy elderly women [57]. The RT group (at $80 \%$ of 1-RM) also had significantly lower LDL$\mathrm{C}$ and TC compared with controls. These favourable changes occurred without concurrent changes in weight or diet.

None of the above studies included patients with abnormal lipid profiles. Unfortunately, no information is available on the effects of RT on subjects with dyslipidaemia. Several earlier studies examined the relationship between RT and plasma lipoprotein levels, with mixed results. In one study, premenopausal women were randomly assigned to an RT program or a control group for 5 months [58]. The RT group showed a significant decrease in TC and LDL-C, while no significant changes were noted in serum HDL-C or TG levels in either group. Changes in body composition showed no significant correlations with changes in TC or LDL-C. Another study determined the effects of 20 weeks of RT on lipid profiles in sixteen untrained males with abnormal lipoprotein-lipid levels and at least two other risk factors for CHD [59]. The training program resulted in no significant changes in plasma concentrations of TG, TC, and HDL-C. These results are in agreement with those that determined the effects of 12 weeks of RT (at $60 \%$ to $70 \%$ of $1-\mathrm{RM}$ ) on lipoprotein-lipid levels in sixteen sedentary obese women [60]. In contrast, another study examined the effects of 16 weeks of high-intensity RT on risk factors for CHD in eleven healthy, untrained males [13]. The RT program resulted in a $13 \%$ increase in HDL-C, a $5 \%$ reduction in LDL-C, and an $8 \%$ decrease in the TC/HDL-C ratio, despite not showing changes in body weight or percent body fat.

These findings indicate that RT has the potential to lower risk factors for $\mathrm{CHD}$, independent of changes in body weight or body composition. The results of a prospective study that focused on lipid and lipoprotein levels in previously sedentary men and women undergoing 16 weeks of RT were similar [61]. Women participants demonstrated a $9.5 \%$ reduction of TC, a $17.9 \%$ decrease in LDL-C, and a $28.3 \%$ lowering of TG. Among the men, LDL-C was reduced by $16.2 \%$, while the ratios of TC and LDL-C versus HDL-C were lowered by $21.6 \%$ and $28.9 \%$, respectively. Thus, RT may result in favourable changes in lipid and lipoprotein levels in previously sedentary men and women. However, limitations exist; only one of the above-mentioned studies was conducted with subjects with dyslipidaemia, and no information is available about the effect of RT on patients with dyslipidaemia alone.

2.3.2. Type 2 Diabetes. Most available studies relate to AET in the treatment of insulin resistance (IR) and type 2 diabetes (T2D). Several systematic reviews focused on the relationship between exercise and/or physical activity and glycemic control in patients with T2D [62-64]. Results indicated that physical training significantly improves glycemic control and reduces visceral adipose tissue and plasma TG in people with T2D, even without weight loss.

RT has been shown to improve insulin-stimulated glucose uptake in patients with impaired glucose tolerance or manifest T2D [48]. RT, and subsequent increases in muscle mass, may improve glucose and insulin responses to a glucose load in healthy individuals $[65,66]$ and in diabetic men and women $[67,68]$ and improves insulin sensitivity in diabetic or insulin-resistant middle-aged and older men and women [68-71]. In addition, high-intensity RT has been found to decrease glycosylated haemoglobin (HbA1c) levels in diabetic men and women, regardless of age $[21,22,72-$ 76].

A recent meta-analysis of 27 randomized controlled trials examined the effects of different modes of exercise on glucose control, and risk factors for complications in patients with T2D [77]. Results demonstrated that differences among the effects of AET, RT, and combined training on HbA1c were minor. For training lasting $\geq 12$ weeks, the overall effect was a small beneficial reduction (HbA1c $0.8 \% \pm 0.3 \%)$. Aerobic and combined exercise had small or moderate effects on blood pressure (BP). All three modes of exercise produced trivial or unclear effects on blood lipids. The effects of RT on glycemic control and risk factors associated with CVD in T2D were small (HbA1c), unclear (BP), or trivial (blood lipids). Findings supported the notion that combined training was generally superior to RT alone.

The clinical significance of a $0.5 \%$ decrease in HbAlc can be gauged by examining large prospective intervention studies investigating morbidity and mortality outcomes in people with T2D [78]. Data suggests that a $1 \%$ rise in HbA1c represents a $21 \%$ increase in risk for any diabetes-related death, a $14 \%$ increased risk for myocardial infarction, and a $37 \%$ increased risk for microvascular complications. The impact of a decrease of $0.5 \%$ HbAlc equates to a $50 \%$ improvement towards a target value of $7 \% \mathrm{HbA} 1 \mathrm{c}$, and a $25 \%$ improvement towards a normal value of $6 \% \mathrm{HbA} 1 \mathrm{c}$, for a person diagnosed with $8 \% \mathrm{HbAlc}$.

It is unclear whether an improvement in glycemic control can be maintained in the longer term. For example, in the 6-month postintervention follow-up period reported by one author [79], participants continuing with supervised RT (at $70 \%$ to $80 \%$ of $1-\mathrm{RM}$ ) maintained the improvement in glycemic control, whilst in a 6-month home-based follow-up group, the improvements were lost [80]. The hypothesized reason for this difference is the difficulty of motivating people with T2D to maintain RT prescriptions as part of a regular lifestyle.

In another study [22], the combination of RT (at $70 \%$ to $80 \%$ of $1-\mathrm{RM}$ ) and moderate dietary restriction was associated with a threefold greater decrease in HbAlc levels after 6 months compared with moderate weight loss without RT. This result was not mediated by concomitant reductions in body weight, waist circumference, and FM. It is apparent that an increase in LBM after RT may be an important mediator in improved glycemic control. One study specifically discussed the effects of an increase in the number of GLUT4 transporters [48], because the transporter 
protein GLUT4 expression at the plasma membrane is related to fibre volume in human skeletal muscle fibres [81]. A further study found that the improvement in LBM after a 10week moderate RT-program had a greater impact on HbAlc levels than the reduction in FM, suggesting that increases in muscle mass improved glycemic control [72]. Furthermore, RT-induced changes in HbAlc have been inversely correlated with changes in the quadriceps cross-sectional area [71]. It has been proposed that hyperglycemia has a direct adverse effect on muscle contractile function and force generation [82].

A recent meta-analysis sought to investigate the existence of a dose-response relationship between intensity, duration, and frequency of RT and the metabolic clustering in patients with T2D [83]. Findings demonstrated that RT significantly reduced glycated hemoglobin by $0.48 \% \mathrm{HbAlc}$ ( $95 \%$ CI: 0.76 to $-0.21, P=.0005)$, fat mass by $2.33 \mathrm{~kg}(95 \% \mathrm{CI}:-4.71$ to $0.04, P=.05)$, and systolic BP by $6.19 \mathrm{mmHg}(95 \% \mathrm{CI}$ : 1.00 to $11.38, P=.02$ ). There was no statistically significant effect of RT on TC, HDL-C, LDL-C, TG, and diastolic BP. It appears that RT regimes of longer duration are most beneficial, whilst higher intensity more likely has a harmful effect on glycemic control. The meta-analysis confirmed the notion that RT does not increase BP (as was once thought), and that RT may even benefit resting BP. The BP-lowering effect of RT seems to be independent of weight loss and is believed to be mediated via reduced sympathetically induced vasoconstriction in the trained state $[84,85]$. It should be noted that a decrease of approximately $6.2 \mathrm{mmHg}$ for resting systolic BP is significant, since a reduction of as little as $3 \mathrm{mmHg}$ in systolic BP has been estimated to reduce $\mathrm{CHD}$ by $5-9 \%$, stroke by $8-14 \%$, and all-cause mortality by $4 \%$ [86]. Progressively higher volumes of RT may reduce resting systolic BP, and more significantly, diastolic BP. Interpretive caution is warranted, due to the fact that the above analyses were based on a limited number of study groups.

\section{Prescription of Resistance Training}

It is well understood that when performed regularly and with sufficient intensity, RT stimulates skeletal muscle to synthesize new muscle proteins (hypertrophy). However, the effective amount of RT to promote muscle growth in relatively sedentary diseased or aged individuals is an area in need of further investigation. It is believed that 1 to 2 sets of 8 to 12 repetitions per set with an intensity greater that $60 \%$ of 1-repetition maximum (1RM-the maximum load that can be lifted once only throughout a complete range of motion), with 8 to 10 exercises per session and 2 to 3 sessions per week, are likely to be beneficial for maximising the health effects of increased skeletal muscle mass [87]. A recent study examining the effects of systematic RT in the elderly (76.2 \pm 3.2 years) demonstrated that RT consisting of two training sessions per week was at least as efficient as RT involving three trainings sessions per week, provided that the number of sets performed was equal [88]. These findings contradict results of a previous study reporting that RT three days per week elicits superior strength gains when compared with RT two days per week [89]. However, the latter study was low volume: higher frequency produced better results. A more recent review demonstrated that there was no difference in mean rates of increase in the whole muscle cross-sectional area between two and three RT sessions per week for longer periods of training [90]. But, caution is urged on the fact that the methods (machines, dynamometer) of measuring muscle strength and expressing it (absolute, relative to body weight or muscle mass) are not standardized. Thus, the true increases in muscle strength are difficult to determine in research protocols. Therefore, to compare results of different studies, muscle strength should be determined in kilo pound (kp) or Newton (N; SI unit).

Systematic reviews comparing RT frequencies in patients with metabolic or cardiovascular risk revealed no apparent association between RT frequencies and changes in risk factors for CVD [91, 92]. However, it should be noted that only a few studies were conducted with subjects with metabolic risk, and most of the included RT studies had a training frequency of three days per week. Regressionbased analyses from recently performed meta-analysis by Strasser et al. suggest there is no apparent association between RT frequency and glycemic control, but indicate a trend to a negative correlation for some outcomes of lipid profile in patients with abnormal glucose regulation [83]. The effect of RT on resting systolic BP and diastolic BP seems to be dose-dependent, since decreases in resting BP were more pronounced when the RT program was of high volume. Apparent was that relatively modest increases in RT frequency had hypotensive effects, since resting BP was reduced to a greater extent when exercising three times per week compared to twice a week [83].

On the basis of a combination of literature findings and in-house laboratory results [21, 79, 88, 93-95], some basic recommendations for the design of programmes for elderly adults with metabolic risk based are provided.

(i) During the first two weeks of exercise, the weights should be kept to a minimal level so that patients learn the exercise techniques. A minimal weight allows muscles to adapt to the training and prevents muscle soreness.

(ii) From the third week, the objective of the training is hypertrophy. Participants should start with three sets per muscle group per week, on 3 nonconsecutive days of the week. One set should consist of 1015 repetitions, without interruption, until severe fatigue occurs and completion of further repetitions is impossible.

(iii) The training load should be systematically increased to keep the maximum possible repetitions between 10 to 15 per set. A repetition maximum of 10 to 15 repetitions corresponds with 60-70\% 1-RM [15].

(iv) The number of sets for each muscle per week should be increased progressively every four weeks by one set to a maximum of 10 sets per week on (Table 1). 
TABLE 1: Systematic adjustment of the weekly RT volume in sets per muscle group per week (S/MG/W) for improvement in maximum strength in rehabilitation, health, and leisure sports.

\begin{tabular}{lcc}
\hline Stage & S/MG/W & Frequency \\
\hline 1 & 1 & $1-2$ \\
2 & 2 & 2 \\
3 & 3 & 2 \\
4 & 4 & 2 \\
5 & 6 & $2-3$ \\
6 & 8 & $2-3$ \\
7 & 10 & $2-3$ \\
\hline
\end{tabular}

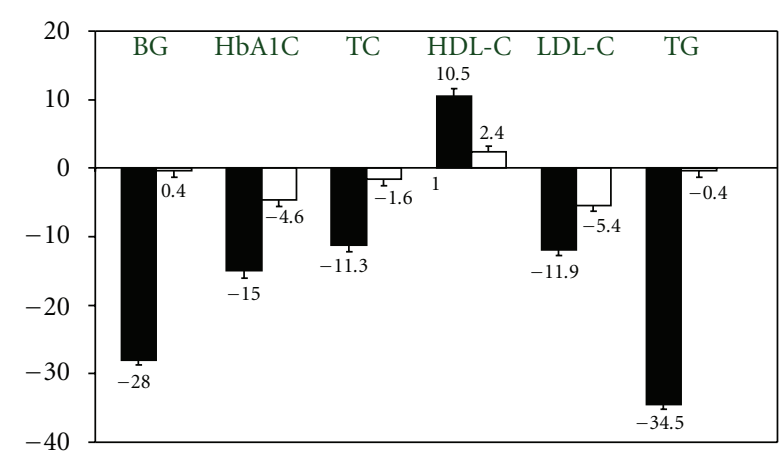

BG: Blood glucose TC: Total cholesterol TG: Plasma triglyceride

HDL-C: High-density lipoprotein cholesterol LDL-C: Low-density lipoprotein cholesterol HbAlc: Glycated hemoglobin
Figure 1: Percent change in metabolic parameters after 4 months RT (black) or AET (white) in patients with T2D. Whiskers represent standard deviation [18].

(v) The RT program should consist of exercises for all major muscle groups. Exercises to strengthen the upper body could include bench press (pectoralis), chest cross (horizontal flexion of the shoulder joint), shoulder press (trapezius), pull downs (latissimus dorsi), bicep curls, tricep extensions, and exercises for abdominal muscles (sit-ups). Lower body exercises could include leg press (quadriceps femoris).

\section{Conclusions}

Based on this review of the literature, there is a strong support for the notion that RT is at least as effective as AET in reducing some major cardiovascular disease risk factors (Figure 1). Findings demonstrate that RT may be an effective alternative to improve body composition and maintain reduced FM in obese patients after exercise training or energy intake restriction. Furthermore, it has been shown that RT preferentially mobilizes the visceral and subcutaneous adipose tissue in the abdominal region. There is now substantial support for RT decreasing glycosylated hemoglobin levels in people with an abnormal glucose metabolism and improves tendency lipoprotein-lipid profiles. Decreased fat mass, improved glycemic control and blood lipid profiles are important for reducing microvascular and macrovascular complications in people with metabolic risk. On this basis, $\mathrm{RT}$ is considered a potential adjunct in the treatment of metabolic disorders by decreasing known major risk factors for metabolic syndromes. As such, RT is recommended in the management of obesity and metabolic disorders.

\section{Conflict of Interests}

The authors have no conflict of interests that are directly relevant to the content of this original research paper.

\section{References}

[1] M. L. Pollock, B. A. Franklin, G. J. Balady et al., "Resistance exercise in individuals with and without cardiovascular disease: benefits, rationale, safety, and prescription: an advisory from the Committee on Exercise, Rehabilitation, and Prevention, Council on Clinical Cardiology, American Heart Association," Circulation, vol. 101, no. 7, pp. 828-833, 2000.

[2] L. S. Pescatello, B. A. Franklin, R. Fagard, W. B. Farquhar, G. A. Kelley, and C. A. Ray, "American College of Sports Medicine position stand. Exercise and hypertension," Medicine and Science in Sports and Exercise, vol. 36, no. 3, pp. 533-553, 2004.

[3] R. J. Sigal, G. P. Kenny, D. H. Wasserman, and C. CastanedaSceppa, "Physical activity/exercise and type 2 diabetes," Diabetes Care, vol. 27, no. 10, pp. 2518-2539, 2004.

[4] S. J. Fitzgerald and G. S. Blair, "Muscular fitness and allcause mortality: prospective observations," Journal of Physical Activity and Health, vol. 1, pp. 17-18, 2004.

[5] R. Jurca, M. J. Lamonte, C. E. Barlow, J. B. Kampert, T. S. Church, and S. N. Blair, "Association of muscular strength with incidence of metabolic syndrome in men," Medicine and Science in Sports and Exercise, vol. 37, no. 11, pp. 1849-1855, 2005.

[6] A. A. Sayer, H. E. Syddall, E. M. Dennison et al., "Grip strength and the metabolic syndrome: findings from the Hertfordshire Cohort Study," QJM, vol. 100, no. 11, pp. 707-713, 2007.

[7] G. R. Hunter, J. P. McCarthy, and M. M. Bamman, "Effects of resistance training on older adults," Sports Medicine, vol. 34, no. 5, pp. 329-348, 2004.

[8] B. F. Hurley and S. M. Roth, "Strength training in the elderly: effects on risk factors for age-related diseases," Sports Medicine, vol. 30, no. 4, pp. 249-268, 2000.

[9] M. E. Nelson, M. A. Fiatarone, C. M. Morganti, I. Trice, R. A. Greenberg, and W. J. Evans, "Effects of high-intensity strength training on multiple risk factors for osteoporotic fractures: a randomized controlled trial," Journal of the American Medical Association, vol. 272, no. 24, pp. 1909-1914, 1994.

[10] T. M. Manini, H. Chen, S. Angleman, et al., "The role of disease in initial differences and longitudinal trajectories of muscle strength and quality among older adults," Gerontologist, vol. 46, p. 153, 2006.

[11] B. C. Clark and T. M. Manini, "Sarcopenia $\neq$ dynapenia," Journals of Gerontology Series A, vol. 63, no. 8, pp. 829-834, 2008.

[12] G. R. Hunter, T. Kekes-Szabo, S. W. Snyder, C. Nicholson, I. Nyikos, and L. Berland, "Fat distribution, physical activity, and cardiovascular risk factors," Medicine and Science in Sports and Exercise, vol. 29, no. 3, pp. 362-369, 1997. 
[13] B. F. Hurley, J. M. Hagberg, A. P. Goldberg et al., "Resistive training can reduce coronary risk factors without altering VO2max or percent body fat," Medicine and Science in Sports and Exercise, vol. 20, no. 2, pp. 150-154, 1988.

[14] R. W. Braith and K. J. Stewart, "Resistance exercise training: its role in the prevention of cardiovascular disease," Circulation, vol. 113, no. 22, pp. 2642-2650, 2006.

[15] M. A. Williams, W. L. Haskell, P. A. Ades et al., "Resistance exercise in individuals with and without cardiovascular disease: 2007 update: a scientific statement from the American Heart Association Council on Clinical Cardiology and Council on Nutrition, Physical Activity, and Metabolism," Circulation, vol. 116, no. 5, pp. 572-584, 2007.

[16] T. You, A. S. Ryan, and B. J. Nicklas, "The metabolic syndrome in obese postmenopausal women: relationship to body composition, visceral fat, and inflammation," Journal of Clinical Endocrinology and Metabolism, vol. 89, no. 11, pp. 5517-5522, 2004.

[17] K. R. Westerterp, "Daily physical activity and ageing," Current Opinion in Clinical Nutrition and Metabolic Care, vol. 3, no. 6, pp. 485-488, 2000.

[18] R. L. Weinsier, G. R. Hunter, R. A. Desmond, N. M. Byrne, P. A. Zuckerman, and B. E. Darnell, "Free-living activity energy expenditure in women successful and unsuccessful at maintaining a normal body weight1-3," American Journal of Clinical Nutrition, vol. 75, no. 3, pp. 499-504, 2002.

[19] B. Rice, I. Janssen, R. Hudson, and R. Ross, "Effects of aerobic or resistance exercise and/or diet on glucose tolerance and plasma insulin levels in obese men," Diabetes Care, vol. 22, no. 5, pp. 684-691, 1999.

[20] A. Sarsan, F. Ardiç, M. Özgen, O. Topuz, and Y. Sermez, "The effects of aerobic and resistance exercises in obese women," Clinical Rehabilitation, vol. 20, no. 9, pp. 773-782, 2006.

[21] E. Cauza, U. Hanusch-Enserer, B. Strasser et al., "The relative benefits of endurance and strength training on the metabolic factors and muscle function of people with type 2 diabetes mellitus," Archives of Physical Medicine and Rehabilitation, vol. 86, no. 8, pp. 1527-1533, 2005.

[22] D. W. Dunstan, R. M. Daly, N. Owen et al., "High-intensity resistance training improves glycemic control in older patients with type 2 diabetes," Diabetes Care, vol. 25, no. 10, pp. 1729 1736, 2002.

[23] G. R. Hunter, C. J. Wetzstein, D. A. Fields, A. Brown, and M. M. Bamman, "Resistance training increases total energy expenditure and free-living physical activity in older adults," Journal of Applied Physiology, vol. 89, no. 3, pp. 977-984, 2000.

[24] G. R. Hunter, D. R. Bryan, C. J. Wetzstein, P. A. Zuckerman, and M. M. Bamman, "Resistance training and intraabdominal adipose tissue in older men and women," Medicine and Science in Sports and Exercise, vol. 34, no. 6, pp. 10231028, 2002.

[25] K. H. Schmitz, M. D. Jensen, K. C. Kugler, R. W. Jeffery, and A. S. Leon, "Strength training for obesity prevention in midlife women," International Journal of Obesity, vol. 27, no. 3, pp. 326-333, 2003.

[26] M. S. Treuth, A. S. Ryan, R. E. Pratley et al., "Effects of strength training on total and regional body composition in older men," Journal of Applied Physiology, vol. 77, no. 2, pp. 614620, 1994.

[27] M. S. Treuth, G. R. Hunter, T. Kekes-Szabo, R. L. Weinsier, M. I. Goran, and L. Berland, "Reduction in intra-abdominal adipose tissue after strength training in older women," Journal of Applied Physiology, vol. 78, no. 4, pp. 1425-1431, 1995.
[28] R. Ross, J. Rissanen, H. Pedwell, J. Clifford, and P. Shragge, "Influence of diet and exercise on skeletal muscle and visceral adipose tissue in men," Journal of Applied Physiology, vol. 81, no. 6, pp. 2445-2455, 1996.

[29] J. E. Donnelly, N. P. Pronk, D. J. Jacobsen, S. J. Pronk, and J. M. Jakicic, "Effects of a very-low-calorie diet and physicaltraining regimens on body composition and resting metabolic rate in obese females," American Journal of Clinical Nutrition, vol. 54, no. 1, pp. 56-61, 1991.

[30] N. P. Pronk, J. E. Donnelly, and S. J. Pronk, "Strength changes induced by extreme dieting and exercise in severely obese females," Journal of the American College of Nutrition, vol. 11, no. 2, pp. 152-158, 1992.

[31] T. A. Wadden, R. A. Vogt, R. E. Andersen et al., "Exercise in the treatment of obesity: effects of four interventions on body composition, resting energy expenditure, appetite, and mood," Journal of Consulting and Clinical Psychology, vol. 65, no. 2, pp. 269-277, 1997.

[32] R. S. Weinstock, H. Dai, and T. A. Wadden, "Diet and exercise in the treatment of obesity: effects of 3 interventions on insulin resistance," Archives of Internal Medicine, vol. 158, no. 22, pp. 2477-2483, 1998.

[33] A. Geliebter, M. M. Maher, L. Gerace, B. Gutin, S. B. Heymsfield, and S. A. Hashim, "Effects of strength or aerobic training on body composition, resting metabolic rate, and peak oxygen consumption in obese dieting subjects," American Journal of Clinical Nutrition, vol. 66, no. 3, pp. 557-563, 1997.

[34] M. E. Sweeney, J. O. Hill, P. A. Heller, R. Baney, and M. DiGirolamo, "Severe vs moderate energy restriction with and without exercise in the treatment of obesity: efficiency of weight loss," American Journal of Clinical Nutrition, vol. 57, no. 2, pp. 127-134, 1993.

[35] L. Vaughan, F. Zurlo, and E. Ravussin, "Aging and energy expenditure," American Journal of Clinical Nutrition, vol. 53, no. 4, pp. 821-825, 1991.

[36] W. J. Evans, "Protein nutrition and resistance exercise," Canadian Journal of Applied Physiology, vol. 26, no. 6, pp. S141-S152, 2001.

[37] R. R. Wolfe, "The underappreciated role of muscle in health and disease," American Journal of Clinical Nutrition, vol. 84, no. 3, pp. 475-482, 2006.

[38] W. W. Campbell, M. C. Crim, V. R. Young, and W. J. Evans, "Increased energy requirements and changes in body composition with resistance training in older adults," American Journal of Clinical Nutrition, vol. 60, no. 2, pp. 167-175, 1994.

[39] R. Pratley, B. Nicklas, M. Rubin et al., "Strength training increases resting metabolic rate and norepinephrine levels in healthy 50- to 65-yr-old men," Journal of Applied Physiology, vol. 76, no. 1, pp. 133-137, 1994.

[40] M. S. Treuth, G. R. Hunter, R. L. Weinsier, and S. H. Kell, "Energy expenditure and substrate utilization in older women after strength training: 24-h calorimeter results," Journal of Applied Physiology, vol. 78, no. 6, pp. 2140-2146, 1995.

[41] W. J. Kraemer, J. S. Volek, K. L. Clark et al., "Influence of exercise training on physiological and performance changes with weight loss in men," Medicine and Science in Sports and Exercise, vol. 31, no. 9, pp. 1320-1329, 1999.

[42] I. Shaw and B. S. Shaw, "Consequence of resistance training on body composition and coronary artery disease risk," Cardiovascular Journal of South Africa, vol. 17, no. 3, pp. 111116, 2006

[43] H. K. Vincent, C. Bourguignon, and K. R. Vincent, "Resistance training lowers exercise-induced oxidative stress and 
homocysteine levels in overweight and obese older adults," Obesity, vol. 14, no. 11, pp. 1921-1930, 2006.

[44] R. Stocker and J. F. Keaney Jr., "Role of oxidative modifications in atherosclerosis," Physiological Reviews, vol. 84, no. 4, pp. 1381-1478, 2004.

[45] G. Parise, S. M. Phillips, J. J. Kaczor, and M. A. Tarnopolsky, "Antioxidant enzyme activity is up-regulated after unilateral resistance exercise training in older adults," Free Radical Biology and Medicine, vol. 39, no. 2, pp. 289-295, 2005.

[46] P. Trayhurn and J. H. Beattie, "Physiological role of adipose tissue: white adipose tissue as an endocrine and secretory organ," Proceedings of the Nutrition Society, vol. 60, no. 3, pp. 329-339, 2001.

[47] S.-K. Park, J.-H. Park, Y.-C. Kwon, H.-S. Kim, M.-S. Yoon, and H.-T. Park, "The effect of combined aerobic and resistance exercise training on abdominal fat in obese middle-aged women," Journal of Physiological Anthropology and Applied Human Science, vol. 22, no. 3, pp. 129-135, 2003.

[48] F. Dela and M. Kjaer, "Resistance training, insulin sensitivity and muscle function in the elderly," Essays in Biochemistry, vol. 42, pp. 75-88, 2006.

[49] R. Ross and J. Rissanen, "Mobilization of visceral and subcutaneous adipose tissue in response to energy restriction and exercise," American Journal of Clinical Nutrition, vol. 60, no. 5, pp. 695-703, 1994.

[50] D. J. Cuff, G. S. Meneilly, A. Martin, A. Ignaszewski, H. D. Tildesley, and J. J. Frohlich, "Effective exercise modality to reduce insulin resistance in women with type 2 diabetes," Diabetes Care, vol. 26, no. 11, pp. 2977-2982, 2003.

[51] P. W. Wilson, R. B. D’Agostino, L. Sullivan, H. Parise, and W. B. Kannel, "Overweight and obesity as determinants of cardiovascular risk: the Framingham experience," Archives of Internal Medicine, vol. 162, no. 16, pp. 1867-1872, 2002.

[52] C. A. Maggio and F. X. Pi-Sunyer, "Obesity and type 2 diabetes," Endocrinology and Metabolism Clinics of North America, vol. 32, no. 4, pp. 805-822, 2003.

[53] F. X. Pi-Sunyer, "The obesity epidemic: pathophysiology and consequences of obesity," Obesity Research, vol. 10, no. 2, pp. 97S-104S, 2002.

[54] R. Kahn, J. Buse, E. Ferrannini, and M. Stern, "The metabolic syndrome: time for a critical appraisal-joint statement from the American Diabetes Association and the European Association for the Study of Diabetes," Diabetes Care, vol. 28, no. 9, pp. 2289-2304, 2005.

[55] D. Boardley, M. Fahlman, R. Topp, A. L. Morgan, and N. McNevin, "The impact of exercise training on blood lipids in older adults," American Journal of Geriatric Cardiology, vol. 16, no. 1, pp. 30-35, 2007.

[56] S. Fenkci, A. Sarsan, S. Rota, and F. Ardic, "Effects of resistance or aerobic exercises on metabolic parameters in obese women who are not on a diet," Advances in Therapy, vol. 23, no. 3, pp. 404-413, 2006.

[57] M. M. Fahlman, D. Boardley, C. P. Lambert, and M. G. Flynn, "Effects of endurance training and resistance training on plasma lipoprotein profiles in elderly women," Journals of Gerontology Series A, vol. 57, no. 2, pp. B54-B60, 2002.

[58] T. W. Boyden, R. W. Pamenter, S. B. Going et al., "Resistance exercise training is associated with decreases in serum low-density lipoprotein cholesterol levels in premenopausal women," Archives of Internal Medicine, vol. 153, no. 1, pp. 97100, 1993.

[59] P. F. Kokkinos, B. F. Hurley, M. A. Smutok et al., "Strength training does not improve lipoprotein-lipid profiles in men at risk for CHD," Medicine and Science in Sports and Exercise, vol. 23, no. 10, pp. 1134-1139, 1991.

[60] J. M. Manning, C. R. Dooly-Manning, K. White et al., "Effects of a resistive training program on lipoprotein-lipid levels in obese women," Medicine and Science in Sports and Exercise, vol. 23, no. 11, pp. 1222-1226, 1991.

[61] L. Goldberg, D. L. Elliot, R. W. Schutz, and F. E. Kloster, "Changes in lipid and lipoprotein levels after weight training," Journal of the American Medical Association, vol. 252, no. 4, pp. 504-506, 1984.

[62] N. G. Boulé, E. Haddad, G. P. Kenny, G. A. Wells, and R. J. Sigal, "Effects of exercise on glycemic control and body mass in type 2 diabetes mellitus: a meta-analysis of controlled clinical trials," Journal of the American Medical Association, vol. 286, no. 10, pp. 1218-1227, 2001.

[63] R. J. Sigal, G. P. Kenny, D. H. Wasserman, and C. CastanedaSceppa, "Physical activity/exercise and type 2 diabetes," Diabetes Care, vol. 27, no. 10, pp. 2518-2539, 2004.

[64] D. E. Thomas, E. J. Elliott, and G. A. Naughton, "Exercise for type 2 diabetes mellitus," Cochrane Database of Systematic Reviews, vol. 3, Article ID CD002968, pp. 1-90, 2006.

[65] J. P. Miller, R. E. Pratley, A. P. Goldberg et al., "Strength training increases insulin action in healthy 50- to 65-yr-old men," Journal of Applied Physiology, vol. 77, no. 3, pp. 11221127, 1994.

[66] M. A. Smutok, C. Reece, P. F. Kokkinos et al., "Aerobic versus strength training for risk factor intervention in middle-aged men at high risk for coronary heart disease," Metabolism, vol. 42, no. 2, pp. 177-184, 1993.

[67] L. M. Fenicchia, J. A. Kanaley, J. L. Azevedo Jr. et al., "Influence of resistance exercise training on glucose control in women with type 2 diabetes," Metabolism, vol. 53, no. 3, pp. 284-289, 2004.

[68] J. Ibañez, M. Izquierdo, I. Argüelles et al., “Twice-weekly progressive resistance training decreases abdominal fat and improves insulin sensitivity in older men with type 2 diabetes," Diabetes Care, vol. 28, no. 3, pp. 662-667, 2005.

[69] N. Brooks, J. E. Layne, P. L. Gordon, R. Roubenoff, M. E. Nelson, and C. Castaneda-Sceppa, "Strength training improves muscle quality and insulin sensitivity in Hispanic older adults with type 2 diabetes," International Journal of Medical Sciences, vol. 4, no. 1, pp. 19-27, 2007.

[70] T. Ishii, T. Yamakita, T. Sato, S. Tanaka, and S. Fujii, "Resistance training improves insulin sensitivity in NIDDM subjects without altering maximal oxygen uptake," Diabetes Care, vol. 21, no. 8, pp. 1353-1355, 1998.

[71] A. S. Ryan, D. E. Hurlbut, M. E. Lott et al., "Insulin action after resistive training in insulin resistant older men and women," Journal of the American Geriatrics Society, vol. 49, no. 3, pp. 247-253, 2001.

[72] J. C. Baldi and N. Snowling, "Resistance training improves glycaemic control in obese type 2 diabetic men," International Journal of Sports Medicine, vol. 24, no. 6, pp. 419-423, 2003.

[73] C. Castaneda, J. E. Layne, L. Munoz-Orians et al., "A randomized controlled trial of resistance exercise training to improve glycemic control in older adults with type 2 diabetes," Diabetes Care, vol. 25, no. 12, pp. 2335-2341, 2002.

[74] J. Eriksson, S. Taimela, K. Eriksson, S. Parviainen, J. Peltonen, and U. Kujala, "Resistance training in the treatment of noninsulin-dependent diabetes mellitus," International Journal of Sports Medicine, vol. 18, no. 4, pp. 242-246, 1997.

[75] A. Honkola, T. Forsén, and J. Eriksson, "Resistance training improves the metabolic profile in individuals with type 2 diabetes," Acta Diabetologica, vol. 34, no. 4, pp. 245-248, 1997. 
[76] R. J. Sigal, G. P. Kenny, N. G. Boulé et al., "Effects of aerobic training, resistance training, or both on glycemic control in type 2 diabetes: a randomized trial," Annals of Internal Medicine, vol. 147, no. 6, pp. 357-369, 2007.

[77] N. J. Snowling and W. G. Hopkins, "Effects of different modes of exercise training on glucose control and risk factors for complications in type 2 diabetic patients: a meta-analysis," Diabetes Care, vol. 29, no. 11, pp. 2518-2527, 2006.

[78] I. M. Stratton, A. I. Adler, H. A. W. Neil et al., "Association of glycaemia with macrovascular and microvascular complications of type 2 diabetes (UKPDS 35): prospective observational study," British Medical Journal, vol. 321, no. 7258, pp. 405-412, 2000.

[79] E. Cauza, U. Hanusch-Enserer, B. Strasser, K. Kostner, A. Dunky, and P. Haber, "The metabolic effects of long term exercise in type 2 diabetes patients," Wiener Medizinische Wochenschrift, vol. 156, no. 17-18, pp. 515-519, 2006.

[80] D. W. Dunstan, R. M. Daly, N. Owen et al., "Home-based resistance training is not sufficient to maintain improved glycemic control following supervised training in older individuals with type 2 diabetes," Diabetes Care, vol. 28, no. 1, pp. 3-9, 2005.

[81] M. Gaster, W. Vach, H. Beck-Nielsen, and H. D. Schrøder, "GLUT4 expression at the plasma membrane is related to fibre volume in human skeletal muscle fibres," APMIS, vol. 110, no. 9, pp. 611-619, 2002.

[82] I. Helander, H. Westerblad, and A. Katz, "Effects of glucose on contractile function, $\left[\mathrm{Ca}^{2+}\right]_{\mathrm{i}}$, and glycogen in isolated mouse skeletal muscle," American Journal of Physiology, vol. 282, no. 6, pp. C1306-C1312, 2002.

[83] B. Strasser, U. Siebert, and W. Schobersberger, "Resistance training in the treatment of the metabolic syndrome: a systematic review and meta-analysis of the effect of resistance training on metabolic clustering in patients with abnormal glucose metabolism," Sports Medicine, vol. 40, no. 5, pp. 397 415, 2010.

[84] R. H. Fagard and V. A. Cornelissen, "Effect of exercise on blood pressure control in hypertensive patients," European Journal of Cardiovascular Prevention and Rehabilitation, vol. 14, no. 1, pp. 12-17, 2007.

[85] J. Padilla, J. P. Wallace, and S. Park, "Accumulation of physical activity reduces blood pressure in pre- and hypertension," Medicine and Science in Sports and Exercise, vol. 37, no. 8, pp. 1264-1275, 2005.

[86] P. K. Whelton, J. He, L. J. Appel et al., "Primary prevention of hypertension: clinical and public health advisory from the National High Blood Pressure Education Program," Journal of the American Medical Association, vol. 288, no. 15, pp. 1882$1888,2002$.

[87] M. S. Feigenbaum and M. L. Pollock, "Prescription of resistance training for health and disease," Medicine and Science in Sports and Exercise, vol. 31, no. 1, pp. 38-45, 1999.

[88] M. Wieser and P. Haber, "The effects of systematic resistance training in the elderly," International Journal of Sports Medicine, vol. 28, no. 1, pp. 59-65, 2007.

[89] R. W. Braith, J. E. Graves, M. L. Pollock, S. L. Leggett, D. M. Carpenter, and A. B. Colvin, "Comparison of 2 vs 3 days/week of variable resistance training during 10- and 18week programs," International Journal of Sports Medicine, vol. 10, no. 6, pp. 450-454, 1989.

[90] M. Wernbom, J. Augustsson, and R. Thomeé, “The influence of frequency, intensity, volume and mode of strength training on whole muscle cross-sectional area in humans," Sports Medicine, vol. 37, no. 3, pp. 225-264, 2007.
[91] K. Tambalis, D. B. Panagiotakos, S. A. Kavouras, and L. S. Sidossis, "Responses of blood lipids to aerobic, resistance, and combined aerobic with resistance exercise training: a systematic review of current evidence," Angiology, vol. 60, no. 5, pp. 614-632, 2009.

[92] M. A. Tresierras and G. J. Balady, "Resistance training in the treatment of diabetes and obesity: mechanisms and outcomes," Journal of Cardiopulmonary Rehabilitation and Prevention, vol. 29, no. 2, pp. 67-75, 2009.

[93] B. Strasser, P. Haber, C. Strehblow, and E. Cauza, "The benefit of strength training on arterial blood pressure in patients with type 2 diabetes mellitus measured with ambulatory 24-hour blood pressure systems," Wiener Medizinische Wochenschrift, vol. 158, no. 13-14, pp. 379-384, 2008.

[94] E. Cauza, C. Strehblow, S. Metz-Schimmerl et al., "Effects of progressive strength training on muscle mass in type 2 diabetes mellitus patients determined by computed tomography," Wiener Medizinische Wochenschrift, vol. 159, no. 5-6, pp. 141$147,2009$.

[95] B. Strasser, M. Keinrad, P. Haber, and W. Schobersberger, "Efficacy of systematic endurance and resistance training on muscle strength and endurance performance in elderly adults-a randomized controlled trial," Wiener Klinische Wochenschrift, vol. 121, no. 23-24, pp. 757-764, 2009. 


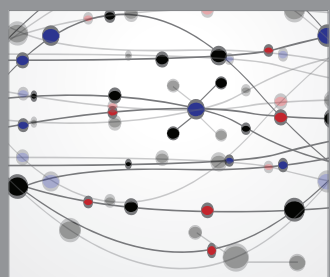

The Scientific World Journal
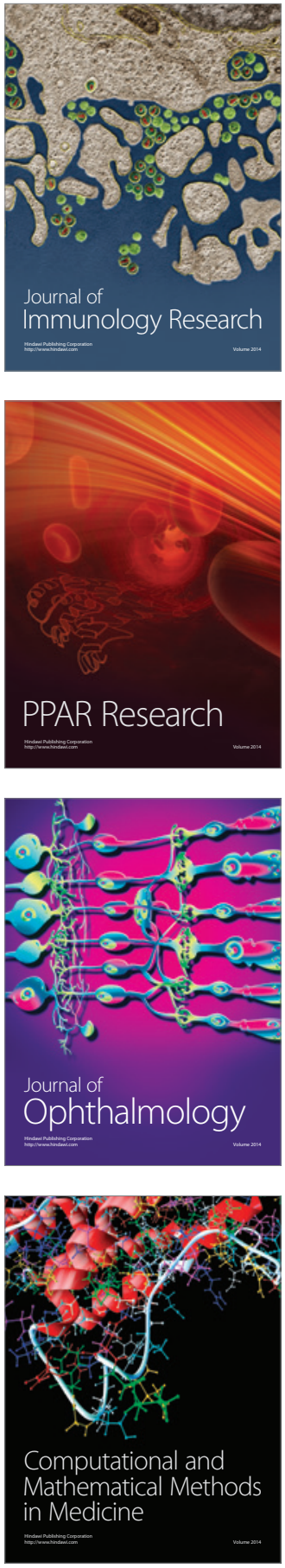

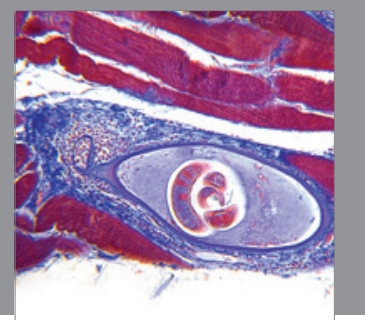

Gastroenterology

Research and Practice
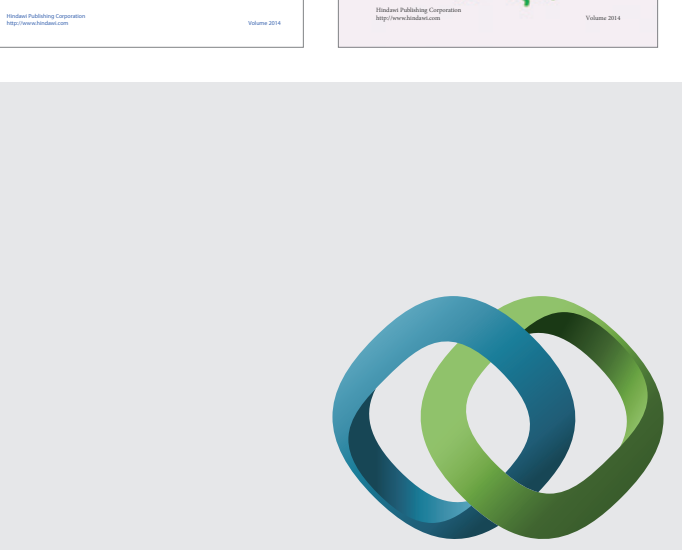

\section{Hindawi}

Submit your manuscripts at

http://www.hindawi.com
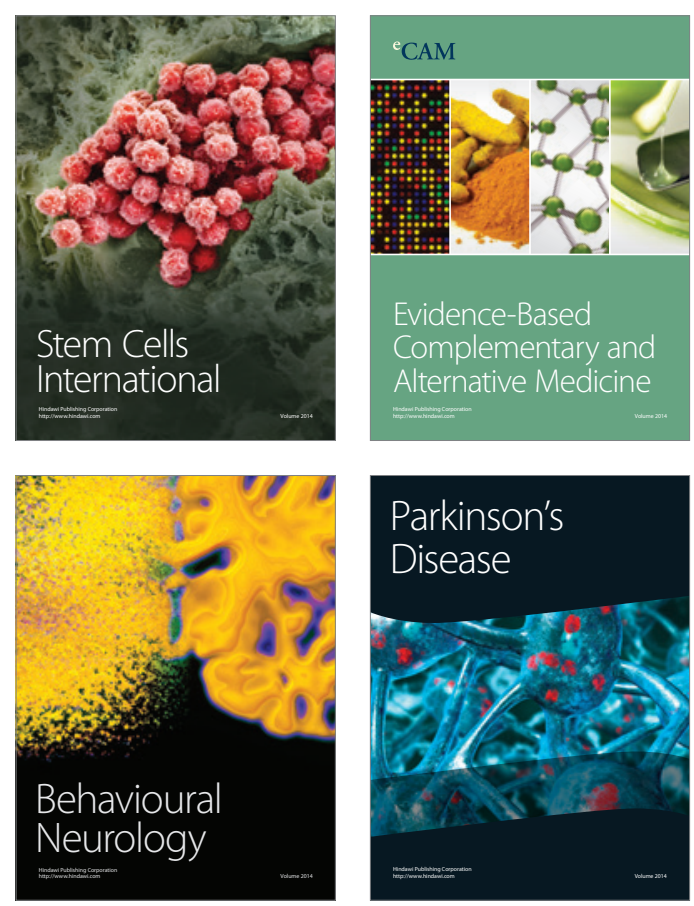

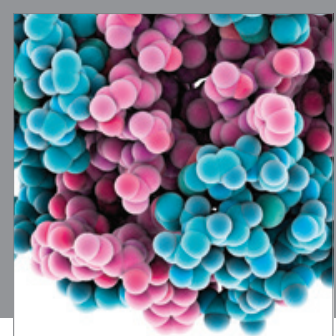

Journal of
Diabetes Research

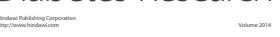

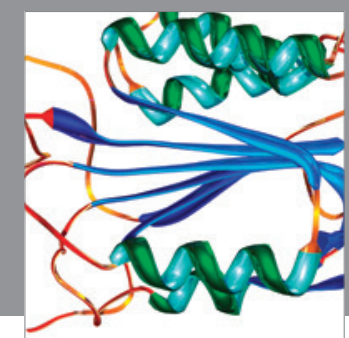

Disease Markers
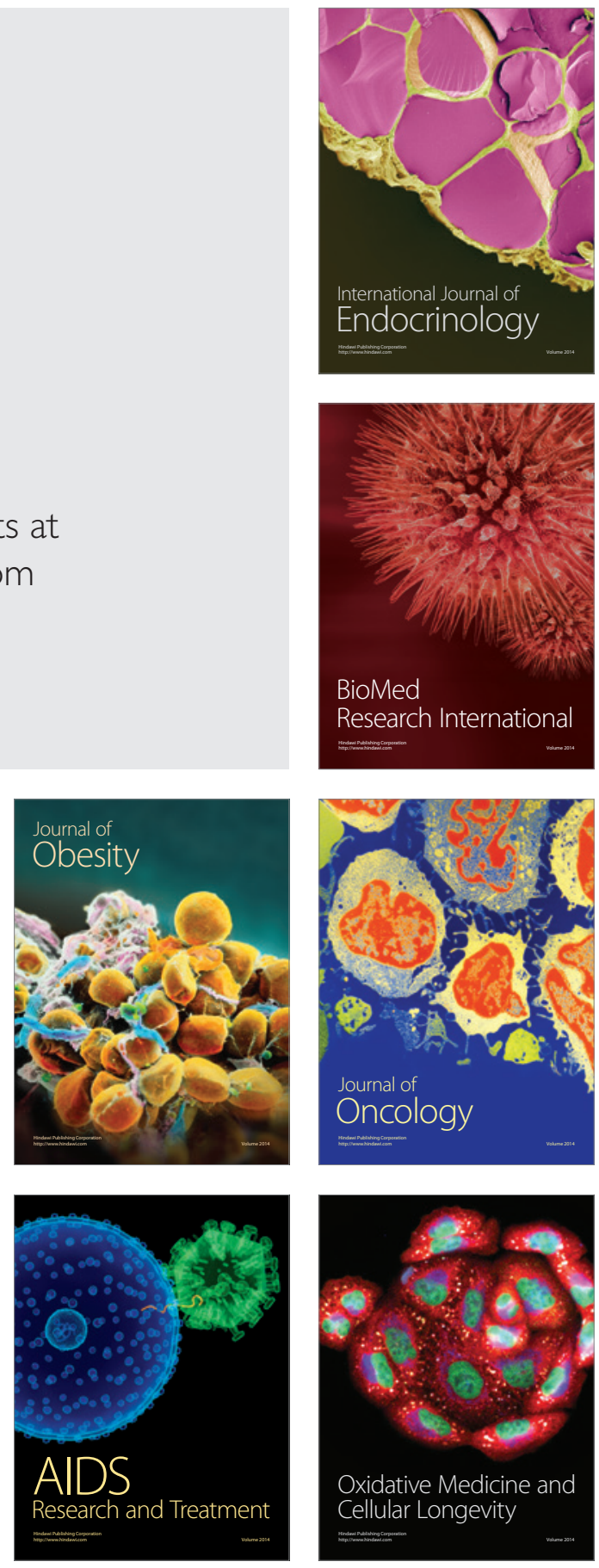